\title{
CHANGING TECHNOLOGICAL ENVIRONMENTS: IMPACT AND INFLUENCES ON YOUTH IN THANE CITY
}

\author{
Neha Shrirang Abhyankar \\ Research Scholar \\ Department of Commerce and Research Centre \\ Savitribai Phule Pune University, India
}

\begin{abstract}
The ubiquitous presence of social media in the day to day life and activities of the youth today due to the advancement of technology and its easy accessibility is obvious. One needs to understand the effects it has on the psychology and perceptions of such students in the age group of 18-24 and the effects it has on their overall mental wellbeing and health. What needs to be examined is the extent and effect of the influence, its pros and cons, its impact on the youth and identification of specific issues so as to aid in the process of finding ways and means to tackle a phenomenon that is here to stay.
\end{abstract}

Keywords: Psychology, Social Media, Perceptions, Technology, Impact.

Cite this article: Neha Shrirang.Abhyankar, Changing Technological Environments: Impact and Influences on Youth in Thane City, International Journal of Management (IJM)pp;51-59; http://iaeme.com/Home/issue/IJM?Volume=10\&Issue=1

\section{INTRODUCTION}

The presence of social media is expanding in India and all over the world. This type of means of communication and methods of keeping in touch has come into existence and flourished in the last $12-15$ years.

The age group of 12 to 24 years is normally termed as the formative period in a person's life. This age is the impressionable age and influences and impacts of any kind of opinion forming, which may last for a long time. Most education, introduction to life values, interaction with society beyond the family and immediate circle, professional knowledge and such other factors are of prominence. The physical and hormonal changes happening in this age are also significant and go on to comprise the mental makeup of an individual, thinking patterns and processes and the outlook towards life and future.

Today's youth is using social media for various purposes. A few have been represented here: 


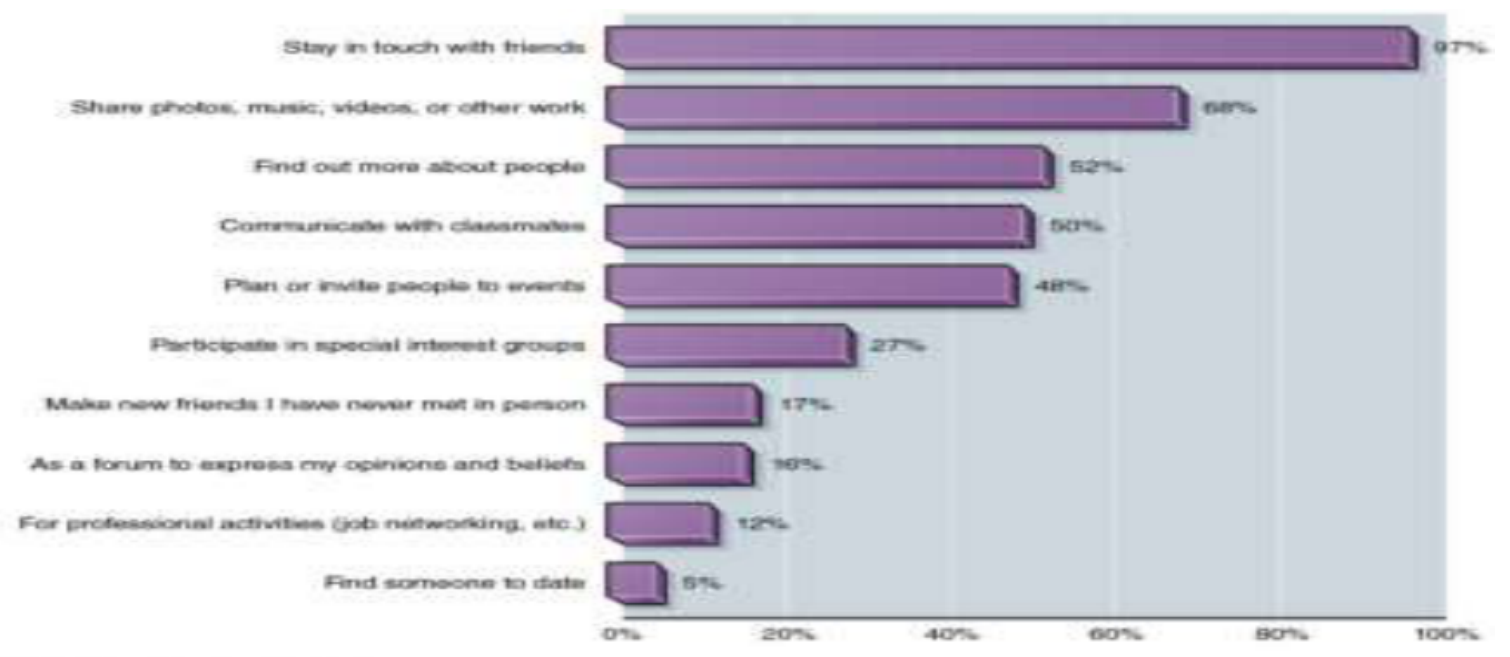

Digital technologies have been observed to impact social and emotional lives. It therefore becomes important to divert attention towards the inputs and exposure that are the molding factors in this new generation. As parents and teachers, especially, educating the youth, creating awareness and developing a proper culture for handling such factors becomes one of the primary responsibilities. The quality and content of the information supplied, and the manner of its supply also becomes relevant.

Technology has enabled us to keep in touch with friends and family is an instant manner. However, the question that bothers parents and social scientists alike is what kind of influence exposure to ever changing technology and its easy and affordable access have on the mental health and overall well-being, especially among the students/ young adults.

This brings one to the topic under discussion: what kind of psychological influences are observed in the youth today. This generation of urban youth have the advantages of easy access to technology through the World Wide Web and IT enabled services. These technologies and devices are introduced at an early age, both systematically through academic syllabus as well as practical experiences in the world around them. They develop familiarity and comfort with the technology early and it gets ingrained to become a part of their day to day lives.

Such advancement in technology has resulted in many positive effects, right from booking tickets, taxis, meals, etc. to instant communication with geographically removed places through print and audio-visual means. There have been many positive changes in the social media arena. The basic advantage is of instant connectivity with friends and family through various means like texting, sharing photos and videos, live chatting, etc. There are groups on social media catering to marginalized population like the LGBT community, people with mental illnesses, alcohol and drug abuse cases, etc. And have helped them to cope with their respective problems. The various social media sites also provide information relating to different activities of interest around us, hobby groups, provide a platform for people with similar likes in music, literature, dance, adventure, culture, fashion, community, etc.

The issues, however, crop up with the negatives effects and fall outs of this technology, especially during the formative years. The negatives generally relate to psychological issues which include anxiety and depression, peer pressure in case of non-participation, flawed perceptions, loneliness, compulsive behaviors, etc.

The issues of personality development and social skills are also relevant. 


\section{SIGNIFICANCE OF THE STUDY}

One observes that while going through the profile of an individual on social media, places and pictures posted thereon, it paints a picture that everything in the life of this person is great and enviable. The person goes places, does adventurous things, holidays often and is loved and adored by everyone around. This introduces an element of falsities and mistrust.

Due to continuous communication on social media, including posting and forwarding of photos, videos, messages, etc., people we do not meet on a daily basis, like school friends, relatives, etc. go from being in the warm circle to being in the cold and distant circle of remaining just acquaintances. This extremely warm exchange of likes and comments dries up on a one to one basis and it is difficult to start a proper conversation, telephonically or personally, thereby affecting the soft skills and social skills of individuals.

The study can help understand the need, utility and influences of social media, as it is something we cannot ignore. It can aid in the understanding of thinking and perception patterns in an attempt to devise means to deal with such psychological effects and to further educate the youth about its pros and cons and help create and develop a culture in the technologically empowered social interaction.

\section{OBJECTIVES}

1) To review the different kinds of social media used.

2) To study the influences of such media on the college students in Thane city.

\section{LIMITATIONS}

1) The scope of the study is quite vast as is the population which can be covered under the same. However, a more than average sample has been selected for convenience of working.

2) The topics that can be covered and the depth in which the topic may be studied is quite extensive too. Thus, topics relating only to certain effects are covered in the questionnaire.

3) There are the obvious restrictions of time which restricts the expanse of the study.

4) Opinions expressed by the respondents are their own and may not remain valid as the scope and sample size is changed.

\section{RESEARCH METHODOLOGY}

1) The nature of the study involves direct interaction and feedback from the respondents, thus necessiciating the adoption of collection of data by primary method. The primary data has been collected through the means of a questionnaire, having close ended questions. A more informal discussion was also had with the respondents.

2) The age group for the study will be young adults within the age range of 18 to 24 years and studying in under graduate or post graduate courses in Thane city.

3) The sample size is 55 students spread across different courses.

4) All responses have then been then been tabulated and those directly related to the study have also been represented in a visual format where understanding the data can be easier. The $\mathrm{Z}$ test is applied for measuring the significance of impact.

5) There are certain questions where multiple options may have been selected by the respondent. Naturally, number of responses in such cases will exceed the sample size. 


\section{FINDINGS AND RELATED OBSERVATIONS}

\subsection{What Kind of Social Media platforms do you use?}

Table 1

\begin{tabular}{|c|c|c|c|c|}
\hline WhatsApp & Facebook & Facetime & Snapchat & Any other \\
\hline 49 & 48 & 6 & 26 & 20 \\
\hline
\end{tabular}

WhatsApp is the most popular media as it is a mobile application, facilitating easy and quick exchange of messages, pictures, audio clips, videos and photos. Due to the widespread availability and use of Smartphones, this free application is the most used amongst social media.

Facebook is the next choice as it helps to share posts with all your contacts in one go. Various groups and communities for various hobbies, events and activities can be created and the followers of such 'pages' can be updated in a regular manner. Eg. Radio stations, adventure clubs, college festivals, etc create their 'page' on Facebook which is updated regularly with posts, photos, videos and notices for upcoming activities or discussion on a particular issue.

Other applications are comparatively less popular; however, they command niche audiences.

\subsection{How do you access these platforms?}

Table 2

\begin{tabular}{|c|c|}
\hline Smart Phones & Laptops / Desktops \\
\hline 48 & 20 \\
\hline
\end{tabular}

As mentioned above, mobile smartphones are becoming more of a necessity in these days. The urban youth are exposed to ubiquitous technology at a very early age. The advantages offered by a smartphone coupled with the concern for safety, especially among girl students is promoting its widespread use. Various applications can be accessed through a data connection and an in-built application like Playstore (either Apple, IoS or Android).

Some respondents also carry laptops and internet dongles to help them with projects, assignments, etc and thus access social media from such devices.

\subsection{How much time do you spend on these mediums daily? (Please specify number of minutes / hours on an average during the day)}

Table 3

\begin{tabular}{|c|c|c|c|c|}
\hline \multirow{2}{*}{ WhatsApp } & 30 minutes-1 hours & $1-2$ hours & $2-4$ Hours & $\begin{array}{c}\text { More than } 4 \\
\text { hours }\end{array}$ \\
\cline { 2 - 5 } & 8 & 7 & 10 & 26 \\
\hline \multirow{2}{*}{ Facebook } & 30 minutes-1 hours & $1-2$ hours & $2-4$ Hours & $\begin{array}{c}\text { More than } 4 \\
\text { hours }\end{array}$ \\
\cline { 2 - 5 } & 19 & 14 & 6 & 5 \\
\hline \multirow{2}{*}{ Facetime } & 30 minutes-1 hours & $1-2$ hours & $2-4$ Hours & $\begin{array}{c}\text { More than } 4 \\
\text { hours }\end{array}$ \\
\cline { 2 - 5 } & 4 & 2 & 0 & 4 \\
\hline \multirow{2}{*}{ Snapchat } & 30 minutes-1 hours & $1-2$ hours & $2-4$ Hours & $\begin{array}{c}\text { More than } 4 \\
\text { hours }\end{array}$ \\
\cline { 2 - 5 } & 12 & 6 & 3 & 5 \\
\hline
\end{tabular}


Neha Shrirang Abhyankar

\begin{tabular}{|c|c|c|c|c|}
\hline \multirow{2}{*}{ Any other } & 30 minutes-1 hours & $1-2$ hours & $2-4$ Hours & $\begin{array}{c}\text { More than } 4 \\
\text { hours }\end{array}$ \\
\cline { 2 - 5 } & 5 & 6 & 3 & 7 \\
\hline
\end{tabular}

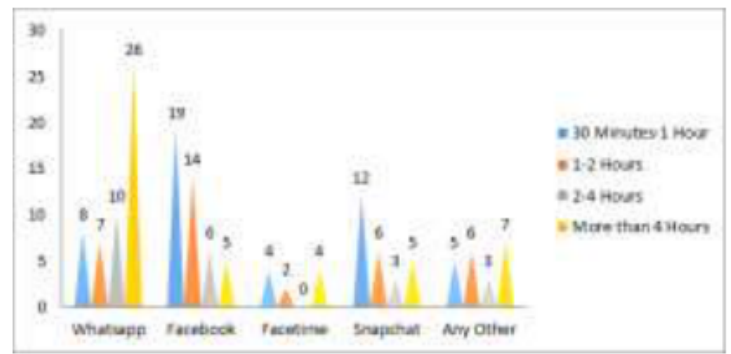

Figure 1

WhatsApp accounts for the maximum amount of time spent on social media. Respondents gave the feedback that checking messages on WhatsApp was compulsive and that they are unable to remain away from it for too long. Facebook and other applications, mostly shopping sites, come next.

This gives an idea of the amount of time spent on such media and gives rise to the question whether it is warranted. It gives rise to the concern whether the use of such platforms is addictive. This time could be spent more productively, and a particular time is assigned for checking social media updates in a particular day.

\subsection{Do your postings reflect your personality?}

Table 4

\begin{tabular}{|c|c|c|c|c|}
\hline To a large extent & Often & Sometimes & Rarely & Never \\
\hline 5 & 14 & 25 & 9 & 2 \\
\hline
\end{tabular}

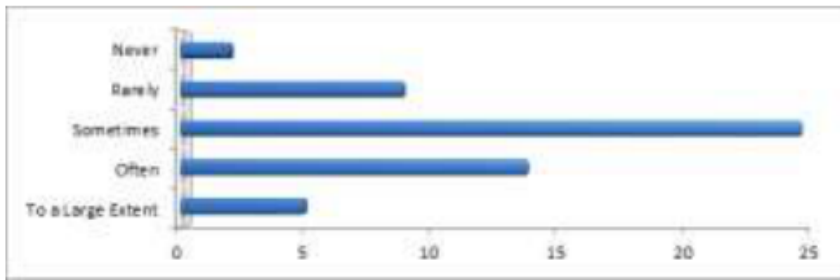

Figure 2

Most of the times, respondents find themselves sharing, posting and commenting on shared media in a way that reflects their personalities, preferences, attitudes and opinions as they see the social media as a platform to express themselves. The audio-visual mediums offered only help in the same (WhatsApp, Facebook, snapchat, etc.).

This may provide an insight into one's thinking pattern, insecurities, etc and certain antisocial elements or nuisance mongers may take disadvantage of the same.

\subsection{While posting videos, comments, photos, etc. do you have a regard as to how others will perceive you?}

Table 5

\begin{tabular}{|c|c|c|c|c|}
\hline Always & Most of the times & Sometimes & Rarely & Never \\
\hline 10 & 21 & 18 & 3 & 3 \\
\hline
\end{tabular}




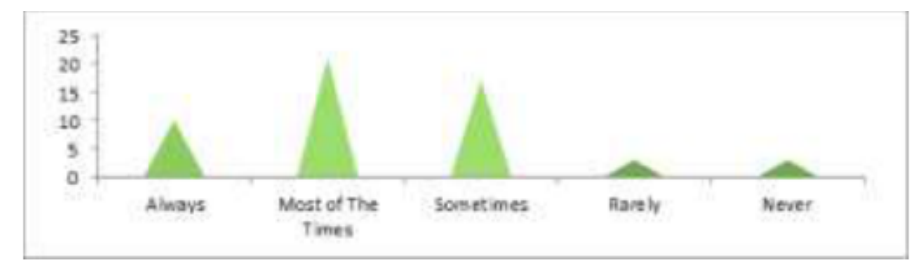

Figure 3

This is the biggest concern when respondents post/share content, as they are conscious of the kind of image they may be portraying in front of peers, seniors, even relative strangers. They try to maintain the image across different platforms.

The respondents feel that that their post/comments, etc. reveal to the other person or create a general impression about them, how they are perceived. Therefore, there is a lot of consciousness as to the kind of photos/videos that are uploaded.

\subsection{Do you get influenced by the videos, comments, photos, etc. of your friends on social media?}

Table 6

\begin{tabular}{|c|c|c|c|c|}
\hline Always & Most of the times & Sometimes & Rarely & Never \\
\hline 3 & 14 & 29 & 6 & 3 \\
\hline
\end{tabular}

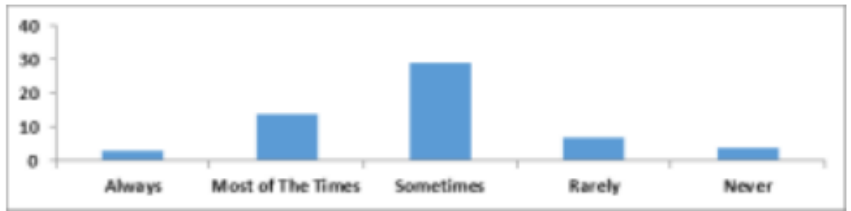

Figure 4

This is a significant finding as the respondents do get affected in a large majority of times depending upon the posts shared. The feeling of negativity and deprivation being the most common while reacting to posts/pictures of peers enjoying themselves when they are on picnics, meals or adventure activities. This may result in them demanding similar benefits and privileges from their parents, rarely appreciating the need for the same. Such unnecessary demands put financial pressure on the parents and can lead to discord on the domestic level.

A feeling of contentedness, happiness and motivation is also experienced by reading positive thought posts by the respondents. Thus, it makes it evident that respondents' moods are highly susceptible to the kind of content shared.

\subsection{Do you experience mood changes / mood swings with the reactions you get to your uploads?}

Table 7

\begin{tabular}{|c|c|c|c|c|}
\hline Always & Most of the times & Sometimes & Rarely & Never \\
\hline 5 & 17 & 14 & 6 & 13 \\
\hline
\end{tabular}


Neha Shrirang Abhyankar

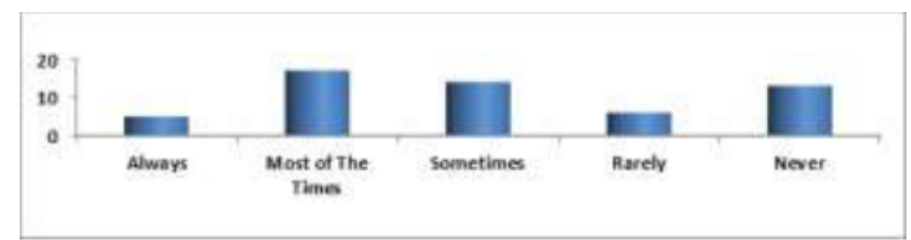

Figure 5

Most of the respondents are looking for a positive and endearing response to their uploads, to reinforce their personality in their virtual social circle. They feel that people around them are interested in knowing what is going on in their lives, their opinions and views.

\subsection{If yes, how strongly do you think they influence you?}

Table 8

\begin{tabular}{|c|c|c|}
\hline To a large extent & To a small extent & No, it will not have any effect \\
\hline 5 & 32 & 11 \\
\hline
\end{tabular}

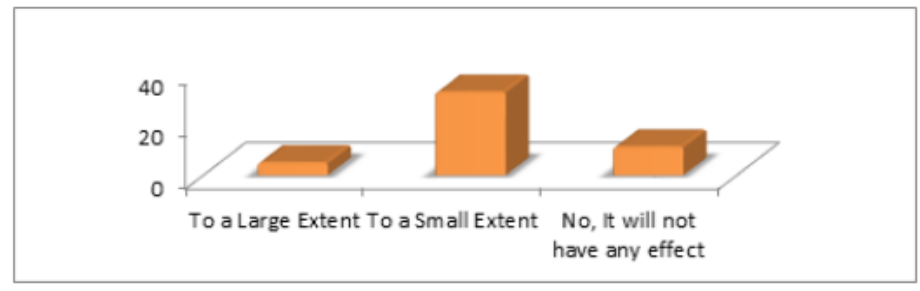

Figure 6

There is significant relation between the question prior and the one dealt with here. Respondents who are unaffected by the reactions to their posts hardly get influenced by them. Thus, respondents not getting affected at all and those getting affected to a small extent are maximum. It may be said that the nature of the influence is quite temporary.

\subsection{Do you think social media has affected one to one interaction / soft skills?}

Table 9

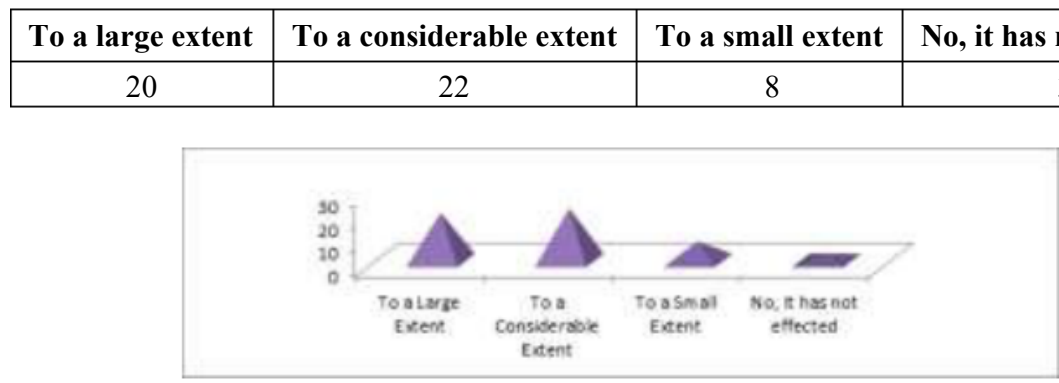

Figure 7

Respondents agree that their social skills, interpersonal skills, public speaking skills are hampered by the extensive use of social media. The extent is different, depending upon basic nature, exposure and motivation to interact on a personal level.

They are unable to start or maintain conversation, especially with people older than them. This hampers their performance in team activities where a more direct approach towards communication is essential. 
Also, they experience difficulties in interacting with people in the cold circle/acquaintances, causing them to remain in the cold circle and not getting closer.

\section{DATA ANALYSIS}

The data was further analyzed to study the actual impact in statistical terms. Question numbers 4 to 7 were selected and the $Z$ test for significance was applied. The findings are as follows:

Table 10

\begin{tabular}{|c|l|l|l|l|}
\hline & \multicolumn{1}{|c|}{ Q4 } & \multicolumn{1}{|c|}{ Q5 } & \multicolumn{1}{c|}{ Q6 } & \multicolumn{1}{|c|}{ Q7 } \\
\hline & & & & \\
\hline To a large extent & 5 & 10 & 3 & 5 \\
\hline Often & 14 & 21 & 14 & 17 \\
\hline Sometimes & 25 & 18 & 29 & 14 \\
\hline Rarely & 9 & 3 & 6 & 6 \\
\hline Never & 2 & 3 & 3 & 13 \\
\hline Total & 55 & 55 & 55 & 55 \\
\hline
\end{tabular}

Table 11

\begin{tabular}{|c|l|l|l|l|l|l|}
\hline $\begin{array}{c}\text { Percentage of } \\
\text { respondents }\end{array}$ & \multicolumn{1}{|c|}{ Q4 } & \multicolumn{1}{|c|}{ Q5 } & \multicolumn{1}{|c|}{ Q6 } & \multicolumn{1}{|c|}{ Q7 } & \multicolumn{1}{|c|}{ Average } & \\
\hline To a large extent & 9.09 & 18.18 & 5.45 & 9.09 & 10.45 & Impact factor \\
\hline Often & 25.45 & 38.18 & 25.45 & 30.91 & 30 & 78.76 \\
\hline Sometimes & 45.45 & 32.73 & 52.73 & 25.45 & 39.09 & \\
\hline Rarely & 16.36 & 5.45 & 10.91 & 10.91 & 10.9 & \\
\hline Never & 3.64 & 5.45 & 5.45 & 23.64 & 9.54 & \\
\hline
\end{tabular}

\section{1. $\mathrm{Z}$ test of significance for single proportion for impact factor $\mathbf{7 8 . 7 6 \%}$}

Null Hypothesis: There is no impact of social media on college students, i.e. Impact factor less than or equal to 0.50

Alternate Hypothesis: There is impact of social media on the college students, i.e. Impact factor is greater than 0.50

Table 12

\begin{tabular}{|c|c|c|c|c|c|}
\hline $\begin{array}{c}\text { Impact factor } \\
\text { proportion } \mathbf{p}\end{array}$ & $\boldsymbol{q}$ & $\boldsymbol{p q} / \boldsymbol{n}$ & $\boldsymbol{S E}=\boldsymbol{s q r t}(\boldsymbol{p q} / \boldsymbol{n})$ & $\boldsymbol{p}-\boldsymbol{P}(.5)$ & $\boldsymbol{z}=(\boldsymbol{p}-\boldsymbol{P}) / \boldsymbol{S E}$ \\
\hline 0.7876 & 0.2124 & 0.003042 & 0.055150413 & 0.2876 & 5.214829535 \\
\hline
\end{tabular}

Calculated value of $\mathrm{Z}$ statistic is greater than 3 hence we reject the null hypothesis and conclude that there is significant impact of social media on the youth.

\section{SUGGESTIONS}

1) The study makes it evident that a substantial amount of time is spent by the respondents on social media on a daily basis. The question arises whether it is warranted or not.

2) The respondents/ youngsters in the age group 18-24 must be encouraged for self-appraisal into the time they spend being on social media platforms and the actual benefit they derive from it. A culture of discipline in accessing social media can thus be inculcated as self-control is the best control.

3) The respondents must be encouraged to assess the utility vs the nuisance value of social media.

4) It is observed that social media has a profound effect on the shaping of self-image which will go a long way into shaping personalities. It also shows that respondents desire a positive feedback and vindication for their actions on social media. It also has an impact on how others 
are perceived. It may not be the full picture as everyone wishes to put their best foot forward and so judging a person from the social profile may convey only part of the picture.

5) Getting affected by the responses of others may hamper the development of a secure and happy personality. One must appreciate the unique attributes of oneself and work towards their betterment rather than being unduly influenced by what others have to say.

\section{CONCLUSION}

Through all the pros and cons and their effect on the youth of Thane city today, one thing is quite clear, that social media is here to stay. Some of us may be able to live without it, some may not. But we are past the stage where we can deny its presence and its impact.

What becomes necessary in this scenario is to train the youngsters to use this tool to their best advantage. Inculcating social media culture, etiquette and a sense of responsibility will help the youth to reap maximum advantage in the long run.

Most of us today are aware of the negative attributes and try to steer clear of them. However, as people who may be able to play a significant role in the formative years of such youngsters, teachers and parents need to be more accepting and open about the use of such platforms for the general as well as specific benefit.

\section{REFERENCE}

[1] Robert J. Barcelona, PhD, Dimensions of Leisure Life Book, Human Kinetics, Inc.2010

[2] Priyadarshini Lamabam and Kunal Chakma, A Study on the Difficulties and Challenges Involved in Creating a Corpus for English-Manipuri Code Mixed Social Media Texts, International Journal of Advanced Research in Engineering and Technology, 9(3), 2018, pp 186-193.

[3] Erin Walsh, M.A. and David Walsh, Ph.D., Retrieved from https://www.psychologytoday.com/us/blog/smartparentingsmarterkids/201709/itscomplicated-teenssocial-media-and-mental-health., 2007

[4] Akha Khou and Kishore Raaj Suresh, A Study on the Role of Social Media Mobile Applications and its Impact on Agricultural Marketing in Puducherry Region, Journal of Management, 5(6), 2018, pp. 28 35 .

[5] Katie Hurley, LCSW, https://www.psycom.net/social-media-teen-mental-health

[6] https://www.bartleby.com/essay/The-Psychological-Impact-of-Social-Networking-F3EHD9YVC

[7] Hilde Hartmann Holsten, University of Oslo, http://sciencenordic.com/how-does-social-media-affectyour-well-being, 2018

[8] Roby Setiadi, Ellin Herlinas, Bara Bagus Priharto Wike Pertiwi and Mohamad Djadjuli, Adaptive Management Strategies on Advances of Information Technology: A Study of the Importance of Social Media Marketing and Customer Database, International Journal of Civil Engineering and Technology, 8(11), 2017, pp. 1050-1058

[9] Charleswiller,https://www.businessinsider.in/Bill-Gates-and-Steve-Jobs-shared-a-surprisingphilosophy-about-tech-and-it-should-have-been-a-big-red flag/articleshow/61192216.cms, 2017

[10] Unnati Patel and Dr. Govind B Dave, an Empirical Study of Advertisements of Products on Social Media Platforms, Analysing the Sectoral Predictability of Risk and Return in India. International Journal of Management, 7(4), 2016, pp.195-207.

[11] "Sorry-i-was-distracted-the-impact-of-technology-on-socialconnection",https://strategicpsychology.com.au/sorry-i-was-distracted-the-impact-of-technology-onsocial-connection/, 2017

[12] Esther Hepziba. R and Dr. Florence John, an Exploratory Study on the Influence of Social Media Marketing Strategies on Customer Engagement. International Journal of Marketing and Human Resource Management, 8(3), 2017, pp. 1-8.

[13] Technology-can-have-positive-and-negative-impact-on-social interactions,https://us.humankinetics.com/blogs/excerpt/technology-can-have-positive-and-negativeimpact-on-social-interactions, 2016

[14] ChrisMorris,"Istechnologykillingthehumantouch?",https://www.cnbc.com/2015/08/15/gy-killing-thehuman-touch.html, 2015

[15] By The Bottom Line, "Technology is Destroying the Quality of Human Interaction"https://thebottomline.as.ucsb.edu/2012/01/technology-is-destroying-the-quality-of-humaninteraction, 2012 